\title{
Thermodynamic effects of commercially available ice boots
}

\author{
Madison N. Quintanar*, Tess Pu'uwaionalani Millar and Matthew A. Burd \\ Department of Animal Science, California Polytechnic State University, San Luis Obispo, CA 93401, USA
}

\begin{abstract}
The limb of the equine athlete is subjected to all types of various stressors during exercise. To ensure the health of the horse and to prevent the possibility of lameness, it has been a common practice to apply cold therapy to the distal limb of the horse pre- and post-exercise. Commercially available boots are widely available for the application of cold therapy. To test the effectiveness of the boot, 6 healthy performance level sport type horses were exercised at a walk, trot, and canter in a round-pen and then subjected to the application of the ice boot for 20 minutes on a treatment leg, and no ice boot on an untreated leg. Thermal images were taken of the $3^{\text {rd }}$ metacarpal region pre-exercise, postexercise, post-ice boot, and every 2 minutes after until the difference between the temperatures of the control leg and the treatment leg became zero. The images were analyzed using an analysis software (FLIR Tools) to determine the average temperature of the $3^{\text {rd }}$ metacarpal region at each time point. The measured temperatures between treatments were found to be significantly different due to the application of the ice boot, providing evidence that the boot sufficiently cools the leg $(\mathrm{P}<.01)$. Thereafter, a 95\% confidence interval was created to depict the average time it took for the cooled leg to return to average temperature post-ice boot, suggesting that it takes about 14.67 minutes for the difference between the temperatures of the cooled leg versus the non-cooled leg to become zero. This finding is significant to horse owners, trainers, and veterinarians that use this commonly available tool. These findings lend evidence to support the common practice of using cold therapy in treatment of disease in the horse.

Keywords: Cold therapy, Equine, Equine limb, Ice boot, Thermography.
\end{abstract}

\section{Introduction}

The equine athlete is subjected to all types of various stressors during exercise. With any athlete, it is not abnormal to observe heat and possibly swelling postexercise due to continuous stress on the limb. Just as in human medicine, the common practice of applying cold therapy has been used over many years almost universally to prevent and reduce inflammation and injury in the equine limb (Ramey, 1999). For example, cryotherapy is considered an important aspect in the treatment of acute laminitis in the horse (Kullmann et al., 2014).

However, while there are several different types of cold therapy (Van Eps et al., 2004), there has been little research done to provide empirical evidence towards the efficacy of the practice of applying cold therapy with the use of ice boots on the distal limb of the horse. Currently, recommended cryotherapy treatment protocol in the horse is extrapolated from human medicine (Pollitt and Van Eps, 2004). Because of the importance of maintaining limb health in the equine athlete, a commercially available ice boot (Professional's Choice, El Cajon, CA) was produced, defined by a neoprene exterior insulating frozen gel pockets, that, while already put into practice, has yet to be tested for its actual effect on the equine limb.
The use of this ice boot has gained popularity in the equine industry under the common assumption that it effectively cools the limb post-exercise and has lasting effects after the boot has been removed. While it is well documented that cryotherapy is beneficial in the treatment of laminitis (Kullmann et al., 2014), there is little information available to support the widespread use of ice boots.

The objective of this study is to determine the effects of a commercially available cold therapy on the equine limb. We hypothesize that these ice boots sufficiently cool the leg to a degree at which we can measure the difference with a thermal imaging camera before and after the application of the ice boot. Furthermore, we expect to see that the temperature of the limb continues to stay cool for at least 20 minutes following the removal of the boot.

\section{Materials and Methods}

\section{Animals}

A within subjects design was performed at Revelers Ranch Superior Sport Horse Breeding (Turlock, CA) using 6 healthy performance level sport-type horses ages 4 - 19. All horses weighed between $992-1420 \mathrm{lbs}$ without the restriction of feed. All horses moved naturally with four basic gaits: a four-beat walk, and two-beat trot, a three-beat canter, and a gallop. 
All horses are subjected to normal equine animal husbandry conditions and the same routine maintenance care. No drugs were used during the duration of this study including any tranquilizers or any drugs used for inflammation. All horses have their hooves routinely trimmed and shod by their usual farrier. During treatment, the horses were cross-tied on rubber flooring and closely monitored throughout the study for signs of adverse effects or discomfort.

\section{Data Collection}

A rough estimation of the third metacarpal bone length, proximal circumference, middle circumference, and distal circumference of both limbs were measured pretreatment for all six horses. A measuring tape was used for all measurements. Horses were lunged for 1 minute at the walk to the left, 1 minute at the walk to the right, 5 minutes at the trot to the right, and 5 minutes at the trot to the left, 3 minutes at the canter to the left, then 3 minutes at the canter to the right in a round pen on the end of a lunge line pre-treatment. Each horse served as its own control as one foreleg received treatment and the other was left bare.

Control and experimental treatments were assigned by the flip of a coin (heads being control and tails being experimental) to the right limb of each horse, the left was assigned whichever treatment the right limb was not. The frozen ice boot was then applied to the limb as the experimental treatment for 20 minutes, then removed. Infrared thermal images were taken of the dorsal view of the third metacarpal bone pre- and postexercise, then also post-ice boot using a FLIR T620 Thermal Imaging Camera (Wilsonville, OR) to determine the average surface temperature in that area. An example of images taken post-exercise and post-ice boot are shown in Figure 1.

Following these initial measurements, images were also taken of the dorsal view of the third metacarpal bone at every 2 minutes following the removal of the ice boot until the difference in temperature between the control limb and the treatment limb became zero. All treatments and measurements took place on the same day for each horse. The camera measured the atmospheric temperature throughout the study and measured consistently at $18.3^{\circ} \mathrm{C}$.

\section{Data Analysis}

Thermal images taken of each horse's legs were transferred and classified by horse into the FLIR Tools app (FLIR Systems, Inc.) for further analysis as in Figure 2. Using the measurement tools integrated in the app, each image was analyzed for the average surface temperature over the complete third metacarpal bone for the specific point in time.

\section{Statistical Procedures}

Data were then analyzed, using a statistical analysis software (JMP Pro 11), using a paired samples t-test to determine the initial effect of the ice boot on the limb.

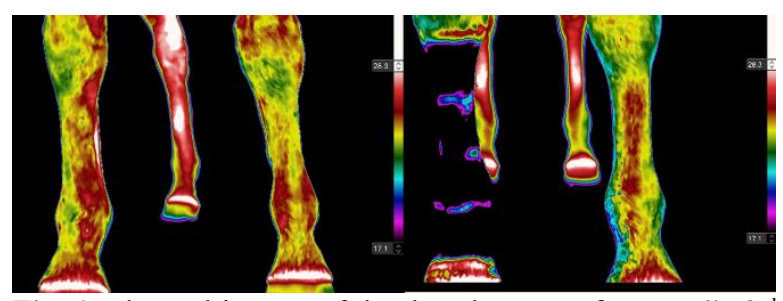

Fig. 1. Thermal images of the dorsal aspect of Horse 6's $3^{\text {rd }}$ metacarpal bones post-exercise and post-ice boot (temperature measured in ${ }^{\circ} \mathrm{C}$ ).

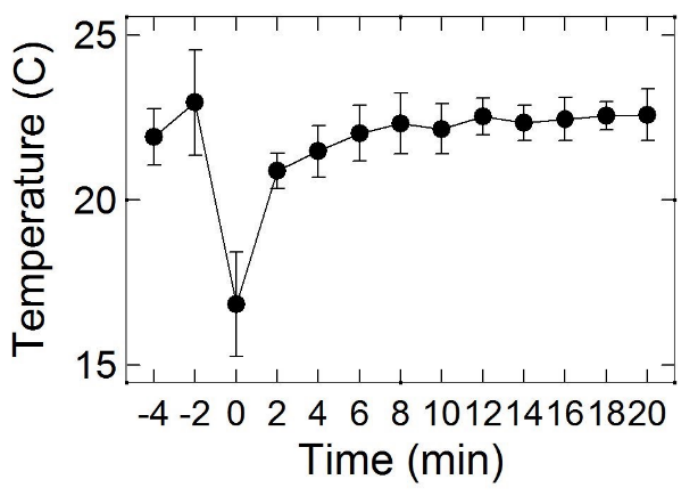

Fig. 2. Mean temperatures between horses of the experimental treatment legs. Data numerically represented in Table 2.

All analyses with $P>.05$ were considered significant. A 95\% Confidence Interval was then constructed to depict the time it takes for the difference in temperature between the control limb and the experimental limb to equal zero.

\section{Results and Discussion}

Third metacarpal circumference and length measurements pre-treatment for each horse are reported in Table 1. Variations of third metacarpal circumference and length measurements between horses were considered minimal for this study.

The difference in temperature of the dorsal aspect of the third metacarpal showed significant treatment effects post-ice boot. The results show a significant difference ( $\mathrm{P}>0.01)$, on average the difference in temperature after the ice boot has been applied is $6.3{ }^{\circ} \mathrm{C}$ cooler than the difference in temperature of the control leg. Subsequently, in all cases, the mean temperature from time 0 (immediately following the removal of the ice boot) increased steadily until approximately 12 minutes post- ice boot where it plateaus at about $22.5^{\circ} \mathrm{C}$ (Fig. 1 and Table 2.

A time effect was observed such that the average time it takes for the difference in temperature between the control limb and the treatment limb to become zero is between 6.9 minutes and 22.5 minutes, the mean time being $14.7 \pm 3.0$ minutes (Table 3 ). 
Table 1. Weight, proximal, middle, distal $3^{\text {rd }}$ metacarpal circumference, and $3^{\text {rd }}$ metacarpal length for each horse.

\begin{tabular}{|c|c|c|c|c|c|c|c|c|c|}
\hline Horse & Weight & $\begin{array}{c}\text { Proximal } \\
\text { Circumference } \\
\text { Rt }\end{array}$ & $\begin{array}{c}\text { Proximal } \\
\text { Circumference } \\
\text { Lt }\end{array}$ & $\begin{array}{c}\text { Middle } \\
\text { Circumference } \\
\text { Rt }\end{array}$ & $\begin{array}{c}\text { Middle } \\
\text { Circumference } \\
\text { Lt }\end{array}$ & $\begin{array}{c}\text { Distal } \\
\text { Circumference } \\
\text { Rt }\end{array}$ & $\begin{array}{c}\text { Distal } \\
\text { Circumference } \\
\text { Lt }\end{array}$ & Length Rt & Length Lt \\
\hline 1 & $1118 \mathrm{lbs}$ & 9 in & 8.5 in & 8 in & 8 in & $11 \mathrm{in}$ & $11 \mathrm{in}$ & $10 \mathrm{in}$ & $10 \mathrm{in}$ \\
\hline 2 & $1256 \mathrm{lbs}$ & $9.5 \mathrm{in}$ & 10 in & 9 in & 8.5 in & 12 in & 12 in & 10.5 in & 10.5 in \\
\hline 3 & $992 \mathrm{lbs}$ & 8.5 in & 8.5 in & $7.5 \mathrm{in}$ & 8 in & 10 in & 10.5 in & $9.5 \mathrm{in}$ & 10 in \\
\hline 4 & $1383 \mathrm{lbs}$ & $9.5 \mathrm{in}$ & 9 in & 9 in & 9 in & 12 in & 12 in & $11 \mathrm{in}$ & $11 \mathrm{in}$ \\
\hline 5 & $1136 \mathrm{lbs}$ & 8.5 in & 8.5 in & 8 in & 8 in & 10.5 in & 10.5 in & 10 in & 10 in \\
\hline 6 & $1420 \mathrm{lbs}$ & 9.5 in & 9.5 in & 9 in & 9 in & $12 \mathrm{in}$ & $12 \mathrm{in}$ & $10.5 \mathrm{in}$ & $10.5 \mathrm{in}$ \\
\hline
\end{tabular}

Table 2. Mean temperatures between the horse's treatment legs per time point and their standard errors. Data graphically represented in Figure 2.

\begin{tabular}{lcc}
\hline TIME POINT & MEAN TEMPERATURES & ST. ERR. \\
\hline Pre-Exercise & 21.9 & 0.77 \\
Post-Exercise & 22.95 & 1.43 \\
Post Ice Boot (T0) & 16.83 & 1.42 \\
T2 & 20.88 & 0.48 \\
T4 & 21.47 & 0.7 \\
T6 & 22.02 & 0.76 \\
T8 & 22.32 & 0.83 \\
T10 & 22.15 & 0.68 \\
T12 & 22.53 & 0.5 \\
T14 & 22.53 & 0.48 \\
T16 & 22.33 & 0.59 \\
T18 & 22.45 & 0.39 \\
\hline
\end{tabular}

Cold therapy has been long thought to prevent and reduce heat and inflammation in soft tissue postexercise in the horse limb. Ice boots are a common method of applying cold therapy to the limb after strenuous and demanding work outs in many sport horse disciplines.

To ensure the health of the performance horse, a commercially available ice boot was produced to meet the demands of the consumer. Although previous research has investigated the effects of cold therapy on the horse limb, no research has been done on this commercial ice boot produced. This study attempts to quantify the usefulness of this ice boot for the purpose of giving empirical evidence to the advantage of the application of the boot post-exercise to prevent and reduce heat and therefore inflammation in the soft tissue of the horses $3^{\text {rd }}$ metacarpal bone. The methodology used in this study was based on common practice of the use of cold therapy in both horses and humans.

The most significant finding of this research suggests that the ice boot properly cools the leg to a degree at which the difference can be measured between a limb exposed to the application of the ice boot and a limb which hasn't been exposed. This is in adherence to a previous study which showed that equine limbs treated with a $4^{\circ} \mathrm{C}$ bandage showed a $6^{\circ} \mathrm{C}$ difference between treated and untreated limbs measured with thermography after the bandage was removed (Ramey, 1999). We can then speculate that due to the reduction of the surface temperature of the limb post-ice boot, there is also a reduction of the temperature of the soft tissue beneath the skin in that area. To investigate further, studies have shown that the application of the standard melting ice cools better than gel wraps and chemical ice envelopes (Van Eps and Orsini, 2016), so a study could be done evaluating the difference between commercially available ice boots and standard melting ice. Results of this study indicate the usefulness of these ice boots on horses to reduce the surface temperature of the horse's legs and furthermore the temperature of the soft tissue beneath the skin. The commonly held industry belief that ice boots effectively cool down the leg are supported by this study. Further studies examining the effects of the ice boots versus other methods of cold therapy may be beneficial. 
Table 3. Temperatures taken pre-exercise, post-exercise, post-ice boot, and every 2 minutes after until the temperature difference between the control and experimental legs equaled zero.

\begin{tabular}{|c|c|c|c|c|c|c|c|c|c|c|c|c|}
\hline \multicolumn{13}{|c|}{ EXPERIMENTAL DATA } \\
\hline \multirow[b]{2}{*}{${ }^{\circ} \mathrm{C}$} & \multicolumn{2}{|c|}{ Horse 1} & \multicolumn{2}{|c|}{ Horse 2} & \multicolumn{2}{|c|}{ Horse 3} & \multicolumn{2}{|c|}{ Horse 4} & \multicolumn{2}{|c|}{ Horse 5} & \multicolumn{2}{|c|}{ Horse 6} \\
\hline & $\mathrm{R}$ & $\mathrm{L}$ & $\mathrm{R}$ & $\mathrm{L}$ & $\mathrm{R}$ & $\mathrm{L}$ & $\mathrm{R}$ & $\mathrm{L}$ & $\mathrm{R}$ & $\mathrm{L}$ & $\mathrm{R}$ & $\mathrm{L}$ \\
\hline Assignment & Control & Tx & $\mathrm{Tx}$ & Control & Control & Tx & $\mathrm{Tx}$ & Control & Control & $\mathrm{Tx}$ & $\mathrm{Tx}$ & Control \\
\hline Pre-Exercise & 24.1 & 24.9 & 21.5 & 20.8 & 22.2 & 21.2 & 20.2 & 20.4 & 20.3 & 20.2 & 23.5 & 24.0 \\
\hline Post-Exercise & 21.7 & 22.9 & 28.0 & 27.7 & 24.4 & 23.8 & 19.7 & 20.3 & 19.1 & 18.4 & 24.9 & 24.7 \\
\hline $\begin{array}{c}\text { Post-Ice Boot } \\
\text { T0 }\end{array}$ & 24.3 & 20.9 & 20.3 & 22.9 & 24.6 & 13.6 & 15.7 & 19.8 & 22.5 & 18.0 & 12.5 & 24.7 \\
\hline $2 \mathrm{~m}$ & 22.9 & 22.3 & 21.1 & 23.1 & 24.5 & 21.9 & 19.1 & 20.8 & 21.4 & 20.8 & 20.1 & 23.4 \\
\hline $4 m$ & 24.5 & 24.3 & 21.9 & 23.2 & 23.7 & 22.0 & 19.3 & 20.9 & 20.8 & 20.9 & 20.4 & 23.4 \\
\hline $6 \mathrm{~m}$ & 24.8 & 24.8 & 23.6 & 24.7 & 23.4 & 21.5 & 19.7 & 20.6 & 21.1 & 21.1 & 21.4 & 23.1 \\
\hline $8 \mathrm{~m}$ & 23.7 & 24.1 & 23.9 & 24.2 & 23.1 & 22.0 & 18.8 & 19.4 & 23.6 & 23.6 & 21.5 & 23.0 \\
\hline $10 \mathrm{~m}$ & 24.8 & 25.1 & 22.7 & 23.1 & 22.5 & 21.9 & 20.1 & 20.9 & 21.2 & 21.5 & 21.6 & 22.8 \\
\hline $12 \mathrm{~m}$ & 21.0 & 21.4 & 22.4 & 23.1 & 23.9 & 22.6 & 19.4 & 19.7 & 20.8 & 21.0 & 22.4 & 24.4 \\
\hline $14 \mathrm{~m}$ & 22.3 & 22.9 & 23.2 & 22.8 & 21.9 & 21.8 & 20.8 & 21.2 & 21.5 & 21.4 & 23.8 & 25.2 \\
\hline $16 \mathrm{~m}$ & 23.8 & 24.4 & 23.0 & 23.3 & 23.1 & 23.3 & 20.2 & 19.9 & 21.9 & 21.7 & 22.1 & 23.0 \\
\hline $18 \mathrm{~m}$ & 22.5 & 22.2 & 23.5 & 23.6 & 22.4 & 21.7 & 21.3 & 21.3 & 23.5 & 23.6 & 23.0 & 23.9 \\
\hline $20 \mathrm{~m}$ & 23.6 & 23.9 & 24.5 & 24.5 & 24.0 & 23.4 & 19.8 & 20.2 & 21.9 & 21.7 & 22.2 & 22.7 \\
\hline $22 \mathrm{~m}$ & & & 24.9 & 25.3 & 24.2 & 23.1 & & & & & 22.4 & 23.2 \\
\hline $24 \mathrm{~m}$ & & & & & & & & & & & 23.6 & 23.6 \\
\hline Time & $6 \mathrm{~m}$ & & $20 \mathrm{~m}$ & & $14 \mathrm{~m}$ & & $18 \mathrm{~m}$ & & $6 \mathrm{~m}$ & & $24 \mathrm{~m}$ & \\
\hline $\begin{array}{l}\text { Temperature } \\
\text { of Ice Boot } \\
\text { Pre- } \\
\text { Application } \\
\text { (Frozen) }\end{array}$ & -2.6 & $\begin{array}{l}\text { Temperature } \\
\text { of Freezer }\end{array}$ & -15.8 & & & & & & & & & \\
\hline
\end{tabular}

\section{Acknowledgements}

We thank Dr. David Young and Revelers Ranch in Turlock, CA for providing us with the facilities and animals to conduct this study. We thank Professional's Choice for providing us with their commercially available ice boots.

\section{Conflict of interest}

The authors declare that there is no conflict of interests.

\section{References}

Kullmann, A., Holcombe, S.J., Hurcombe, S.D., Roessner, H.A., Hauptman, J.G., Geor, R.J. and Belknap, J. 2014. Prophylactic digital cryotherapy is associated with decreased incidence of laminitis in horses diagnosed with colitis. Equine Vet. J. 46, 554-559.

Pollitt, C.C. and Van Eps, A.W. 2004. Prolonged, continuous distal limb cryotherapy in the horse. Equine Vet. J. 36, 216-220.

Ramey, D.W. 1999. Cold therapy in the horse. Equine Pract. 21, 19-21.

Van Eps, A.W., Walters, L.J., Baldwin, G.I., McGarry, M. and Pollitt, C.C. 2004. Distal limb cryotherapy for the prevention of acute laminitis. Clin. Tech. Equine Pract. 3, 64-70.

Van Eps, A.W. and Orsini, J.A. 2016. A comparison of seven methods for continuous therapeutic cooling of the equine digit. Equine Vet. J. 48, 120-124. 